\title{
Self-Identity and Adolescent Return to Sports Post-ACL Injury and Rehabilitation: Will Anyone Listen?
}

\author{
John Nyland, D.P.T., S.C.S., Ed.D., A.T.C., C.S.C.S., F.A.C.S.M., and \\ Brandon Pyle, M.S., A.T.C.
}

\begin{abstract}
Psychological recovery following anterior cruciate ligament (ACL) injury, surgery, and rehabilitation may be influenced by concerns related to self-identity, self-esteem, self-efficacy, health locus of control, fear/avoidance, kinesiophobia, depression, and other emotional or behavioral factors. Through clinical practice guidelines and consensus position articles, knee surgeons, physical therapists, and athletic trainers have greatly improved the process by which physiological musculoskeletal impairment and functional limitation achievement goals translate into evidence-based return to unrestricted sports participation decisions. However, the key psychological indicators or milestones that represent safe return to sports readiness remains poorly understood. The International Classification of Functioning, Disability and Health Model (ICF) provides a helpful framework for generating a more comprehensive decision-making evaluation. The ICF considers patient function as the dynamic interaction between health conditions, environmental factors, and personal factors. Through the use of its common language, the ICF encourages interdisciplinary health care provider communication to more effectively implement team-based, patient-centered care, to better integrate physiological and psychological evaluation and treatment expertise into comprehensive care plans. This article describes the influence of high athletic self-identity on return to sports decision-making among adolescent athletes following ACL injury, surgery, and rehabilitation. Information about adolescence, sports, sports specialization, athletic identity, and more comprehensive return to play decision-making are synthesized into recommendations designed to reduce knee reinjury or new injury risk, and to improve performance among this patient population.
\end{abstract}

\section{Introduction}

$\mathbf{P}$ sychological recovery after anterior cruciate ligament (ACL) injury, surgery, and rehabilitation may include concerns related to self-identity, self-esteem, self-efficacy, health locus of control, fear/avoidance, kinesiophobia, and other factors. ${ }^{1}$ Through clinical practice guidelines and consensus position articles, knee surgeons, physical therapists and athletic trainers have

From the Division of Sports Medicine, Department of Orthopaedic Surgery, University of Louisville, Louisville, Kentucky, U.S.A.; and Athletic Training Program, Kosair Charities College of Health and Natural Sciences, Spalding University, Louisville, Kentucky, U.S.A.

Full ICMJE author disclosure forms are available for this article online, as supplementary material.

Received August 3, 2021; accepted September 15, 2021.

Address correspondence to John Nyland, D.P.T., S.C.S., Ed.D., A.T.C., C.S.C.S., F.A.C.S.M., Athletic Training Program Director and Professor, Kosair Charities College of Health and Natural Sciences, Spalding University, 901 South 4th St., Louisville, KY 40203, U.S.A.E-mail: jnyland@spalding.edu

(C) 2021 THE AUTHORS. Published by Elsevier Inc. on behalf of the Arthroscopy Association of North America. This is an open access article under the CC BY-NC-ND license (http://creativecommons.org/licenses/by-nc-nd/4.0/).

2666-061X/211130

https://doi.org/10.1016/j.asmr.2021.09.042 improved the process by which physiological impairment and functional limitation achievement goals translate into evidence-based decisions to return to unrestricted sports. However, our knowledge of key psychological indicators or achievement milestones indicative of safe return to sports readiness is poorly understood.

Over the years, we have provided health care to many adolescent athletes, with a growing number of them focusing on one sport as their sole self-identity source. These adolescents compete in their sport year-round on both school and select club teams. Within the context of repetitious, high-volume skills training, physiological conditioning, and competition schedules, at best, most of them approach physiological overtraining thresholds, with little time invested in active recovery, tissue healing/remodeling, or psychological recuperation. or many of these athletes assuming the athlete role occurred somewhat insidiously, gradually becoming their sole self-identity, and their primary source of selfesteem. If and when cognitive wellness or performance appraisals occur, they arise solely from the "athletic self" perspective. In association with this, the young athlete too often expresses unrealistic or obsessive 
sports passion that overrides their ability to assess true readiness to return to sport following knee injury or surgery. Given that these athletes are primarily adolescents, treating the variable physical, emotional, and behavioral maturity that they possess can be a daunting task. This article describes the influence of high athletic self-identity on return to sports decision-making among adolescent athletes following ACL injury, surgery, and rehabilitation. Information about adolescence, sports, sports specialization, athletic identity, and more comprehensive return to play decision-making are synthesized into recommendations designed to reduce knee reinjury or new injury risk, and to improve performance among this patient population.

\section{Adolescence}

Although sports are often initiated before adolescence, it is during adolescence that more structured participation occurs with greater frequency, intensity, and total volume, as well as less dedicated recovery time, often coinciding with the athlete sustaining their first injury. But when is adolescence? The American Academy of Pediatrics states that adolescence occurs between 12-21 years of age, with further divisions into early (11-14 years of age), middle (15-17 years of age), and late (18-21 years of age, and beyond). ${ }^{2,3}$ of preeminent importance is that brain development continues well into the third decade of life. ${ }^{4,5}$ Highly variable adolescent athlete sexual maturity, musculoskeletal status, and neurocognitive development between 12 and 21 years of age, with further brain development into the third decade of life, makes clinical advisement and rehabilitation interventions both difficult to plan and administer. Another important consideration during adolescence is that parents or guardians provide primary contributions to the decision-making process. Athlete, parent or guardian, and coach suggestions often blend together into knee injury recovery management decisions. All key stakeholders need to be cognizant that adolescent athletes are not merely small adults. Therefore, they require adequate time for brain developmental recovery and sufficient active rest, recuperation, and reflection time after training or competition (parasympathetic nervous system response) to enhance psychological, as well as physiological growth. Concurrently, coaches who assume an increased interest in the developing athlete may do so largely because they want to win. Some coaches may need to better acknowledge that by necessity, they place the need to win as a higher priority than all other stakeholders, creating a natural conflict of interest with the health status of any one athlete. When parents empower coaches to greater control of their developing adolescent athlete, they may "outsource" parental responsibilities in a potentially unsafe manner. ${ }^{6}$

\section{Why Play Sports?}

Why do adolescents want to play sports? One would think it would be to have fun, participate in a new activity, develop socially, express competitive needs, or to improve general fitness, to name just a few of many other possible reasons. Values attributed to participation in athletics, or learning about "sportsmanship" have traditionally included the work ethic development needed to achieve team and/or individual excellence, develop respect for self and others, humility, teamwork, patience, and/or perseverance, establishing resilience/ coping skills, and learning how to win or lose with honor and dignity. ${ }^{7}$ What we have more frequently observed over recent years is that both the adolescent athlete and their parents or guardians describe that the main reason for choosing one sport was to develop individual "elite-like" skill prowess, obtain a college athletic scholarship, or become a professional athlete..$^{8,9}$ The chance of obtaining an athletic scholarship is very remote, with only about $2 \%$ of high school athletes getting a college sports scholarship, worth on average $<\$ 11,000$ U.S. dollars/year. ${ }^{10}$

Regarding any dream to advance to professional sports, ${ }^{7}$ parents and guardians need to know that in baseball, $11.6 \%$ of college players eventually play professionally, and only .6\% of high school players do; in American football $1.7 \%$ of college players eventually play professionally, and only $.08 \%$ of high school players do; in men's basketball $1.2 \%$ of college players eventually play professionally, and only $.03 \%$ of high school players do; in men's soccer $1.0 \%$ of college players eventually play professionally, and only .04\% of high school players do; in women's basketball, .9\% of college players eventually play professionally, and only $.03 \%$ of high school players do; and in men's ice hockey, $1.3 \%$ of college players eventually play professionally, and only .1\% of high school players do. On the basis of these data, early sport specialization to obtain a college scholarship or to advance to professional sports is a very unlikely scenario. ${ }^{8}$ There are always exceptions, however; this dream is a bit like Don Quixote chasing and fighting his windmill. ${ }^{11}$ From this perspective, parents and guardians are encouraged to think deeply about whether or not potentially giving up many other diverse activities in favor of early sport specialization is truly a worthy trade-off.

\section{Early Specialization}

By not participating in other activities, the adolescent athlete likely will not experience the diverse stressors needed to develop more holistic physical, cognitive, emotional, and behavioral growth. ${ }^{12}$ In our opinion, they begin to focus on sports similarly to how an elite athlete approaches their profession. Over time, this 
"pseudo-elite" training approach begins to supersede any deliberate play, or unstructured activities that normally provide the developing adolescent with the intrinsic motivation, gratification, and enjoyment necessary to better translate early sports participation into healthy long-term recreational athletic or exercise interests as adults. Adolescent athletes who regularly participate in a variety of different team or individual sports or other activities may be at lower injury risk than their peers who specialize early, and they may also be more likely to participate in lifelong physical activities. ${ }^{6,13,14}$ It is important to regularly reassess why one plays sports to be sure that the context, volume, and true reasons for participation match the desired goals.

\section{Athletic Self-Identity and the Adolescent Athlete}

Athletic self-identity represents the degree of strength and exclusivity to which an individual identifies with the athlete role relative to other life activities. ${ }^{15}$ Having a strong identification with sports often pushes athletes to train excessively and, thereby, jeopardize their health. ${ }^{15,16}$ Adolescents who are strongly immersed in athletics, and receive regular participation praise and encouragement, are more likely to focus their selfidentity exclusively on the athlete role. ${ }^{17}$ Among adolescents who possess a strong athletic identity, after knee injury, self-protective changes may need to occur to preserve self-esteem or identity. When they cannot immediately return to sports following knee injury and surgery, their self-identity may be threatened, leading to negative psychological reactions, which may be expressed as eating disorders, illicit behaviors, overaggressiveness, or depression. ${ }^{18}$

Sole athlete role identification during adolescence may lead to reduced health and fitness activities, poorer coping skills, reduced team dynamics appreciation, more constrained athletic movements, joint loading and muscle activation patterns, and less sports culture appreciation later in life. ${ }^{18}$ During late adolescence, sports identity foreclosure usually begins as other academic, social, cognitive, motivational, and emotional affective factors and interests develop. ${ }^{19}$ By avoiding sole identification as an athlete during this important life phase, adolescents who develop more complex self-identities become better equipped to manage both life and sport stresses, and more successfully mediate future successes and failures. To ease the transition away from competitive sports and its potential negative influence on self-identity and selfesteem, college athletes often preemptively reduce their athletic identity before they discontinue competitive sports. ${ }^{20}$ Following ACL reconstruction, Brewer et al. ${ }^{19}$ reported that many patients decreased their athlete role identification with the greatest decrease occurring at 6-12 months postsurgery, and the lowest levels observed at 2 years postsurgery. Although this study did not evaluate return to sports success, athletic identity likely plays a vital role in this process, as return to sports decisions are often made during this time period. By decreasing athlete role identification, slowly or poorly recovering athletes can better control the discrepancy between their self-identity and reduced performance capabilities. ${ }^{19}$ Athletic identity and depression are directly related for injured athletes, but not for uninjured athletes. ${ }^{19,21-23}$

Postinjury depression associated with high athletic identity leads many athletes to react more negatively to injury, imagined or real, than participants with a lesser athletic identity. ${ }^{19,22,23}$ Similar to defense mechanisms used to protect the ego, deidentifying with the athlete role and devaluing one's athletic identity safeguards a person's sense of self when their athletic career is suddenly threatened by injury, or when rehabilitation progress is delayed or poor. ${ }^{24}$ Although self-identity normally possesses many different dimensions, one particular dimension often becomes dominant or preferred, serving as the primary perspective through which all other dimensions are viewed. This identity narrowing usually comes at the expense of exploration and investment in other age-appropriate or available roles. The ascendancy of a single role such as possessing an exclusively athletic self-identity, leads to the neglect or "atrophy" of other roles, exposing the individual to subsequent identity issues, by decreasing or removing other important overall self-esteem and self-concept sources. ${ }^{25,26}$

Normally, adolescents continually reshape their identities through both positive and negative sport experiences (making or muffing plays, winning or losing, increasing or decreasing playing time, developing or failing to develop new skills, etc.). which can influence their performance and dropout or burnout rates. ${ }^{27,28} \mathrm{At}$ some point during this process, they may begin to negotiate a new sense of self as a form of ego selfprotection, which over time helps them prepare for eventual sports retirement. ${ }^{29-31}$ The more time athletes have to prepare, divest from the athlete role, and increase their investment in other defining roles, the less stressful will be the athletic retirement. Individuals who decrease athlete role prominence as a self-protection mechanism before actual sport withdrawal and who actively foster other identity dimensions are better prepared to manage identity issues after athletic retirement. ${ }^{32-34}$ In devoting oneself to other roles, with athletics representing only one subcomponent of a greater self, rather than sacrificing one role in favor of another, it is more likely that excellence will be fostered in both. This challenges the belief that sports excellence requires complete devotion at the expense of well- 
rounded identity development and age-appropriate role experimentation. $^{35}$

Sudden, unexpected sports retirement from knee injury affects not only an individual's athletic identity, but also their overall self-identity. ${ }^{15,22,36,37}$ Athletes who identify most strongly with the athlete role have greater identity difficulties postretirement, particularly when the retirement occurs unexpectedly because of injury. $^{30,31,38}$ Self-identity narrowing among college basketball players may occur as they are influenced by the celebrity and fame that they accrued while in the athlete role. ${ }^{38}$ This athletic self-identity dominance occurs at the expense of academic and social self-identity dimensions, reducing both self-identity complexity and the ability to successfully transition from being an athlete to experiencing other roles after retirement. Among equestrian athletes, self-identity narrowing is associated with the rise of the "glorified athlete", making it difficult for individuals to regain a sense of identity when the athlete role no longer exists. ${ }^{31}$ In studying elite gymnasts, Kerr and Dacyshyn ${ }^{30}$ identified a similar self-redefinition struggle with athletes describing that they drifted toward a "nowhere land", feeling disoriented, with identity loss, and being confused after their sports retirement. Gustafsson et al. $^{39}$ suggested that possession of a performancebased self-esteem, and a narrow, exclusive athlete identity accelerated sports burnout. The strength of athletic identity largely predicts emotional adjustment difficulties across a range of sports upon retirement. ${ }^{40-42}$ Soccer athletes who are depicted by the media as "sporting heroes" likewise have high athletic identities that have been associated with early sports retirement depression. ${ }^{43}$ A similar phenomenon has been observed in youth soccer players who trained at professional academies, where even at 16 years of age, players with high athletic identity levels had difficulty making lifestyle adjustments after athletic retirement. ${ }^{40,44}$

\section{Rehabilitation and the Developing Athlete}

Future developmental research may help explain psychological and behavioral changes within individuals across the life span. ${ }^{45}$ Specific cognitive, emotional, social, and behavioral constructs important to athletically active adolescents include perceptions of self (efficacy, esteem, identity), social support (peers, coaches, parents, guardians), emotions (anxiety, mood, depression, stress), motivations (intrinsic or selfmotivation, extrinsic motivation), and skill levelcompetence.

Because adolescent self-identities are so fragile and often dependent on the sports that they participate in, knee injury, surgery, and rehabilitation can be psychologically traumatizing. ${ }^{46}$ Athletes cognitively appraise many things after they sustain a knee injury, such as the cause, recovery status, how long they will be out, and what social support may be available. To date, these appraisals, and their subsequent influences on adolescent athlete emotions and behaviors, have received limited research attention. In possessing high performance expectations and often irrational decisionmaking, the adolescent athlete may require considerable assistance with the cognitive appraisal process. ${ }^{47}$ Daly et al. $^{48}$ reported that an athletes' cognitive appraisal related directly to their total mood disturbance. Self-worth, self-confidence, self-esteem, and self-efficacy perceptions may each influence the adolescent athlete's sports injury rehabilitation experience. Just as there is a growing appreciation for and understanding of the importance of maintaining physiological system homeostasis during training, ${ }^{49-52}$ perhaps similar research is needed to identify ways to better ensure adolescent athlete psychological homeostasis from a developmental perspective.

Children, adolescents, young, middle, and older adults may each display widely different behavioral and emotional responses to sports injury, surgery, and rehabilitation based on self-perceptions, social influences, motivations, and selfregulation skills. ${ }^{45,53}$ What makes adolescent athletes particularly complex is the high volume of cognitive, emotional, and social growth occurring simultaneously with physical growth over the same time period. Therefore, knee surgeons, physical therapists and athletic trainers must consider each adolescent athlete from their unique developmental perspective, as this may influence their thoughts, emotions, and behaviors.

\section{A Comprehensive Function and Disability Perspective}

With growing appreciation for psychological and environmental influences on health care outcomes, interventions that treat the injured adolescent athlete should adopt a more comprehensive perspective (Fig 1). The International Classification of Functioning, Disability and Health Model (ICF) provides a useful framework for doing this. ${ }^{54}$ The ICF considers patient function as the dynamic interaction between health conditions, environmental factors, and personal factors. Using a common language, the ICF may enhance interdisciplinary health care providers' capacity for developing more integrated, team-based, patient-centered treatment plans. Guiding ICF principles are 1) application to all patients irrespective of health condition, physical, social, or cultural contexts; 2) parity between different "mental or physical" health conditions, with disability not being differentiated by etiology, and shifting from a primary pathology or disease perspective to greater importance being placed on function; 3 ) use of neutral language in reporting positive or negative disability characteristics; and 4) appreciation for physical (i.e., climate, terrain, 


\section{6 yo Lacrosse Player with High Athletic Identity}

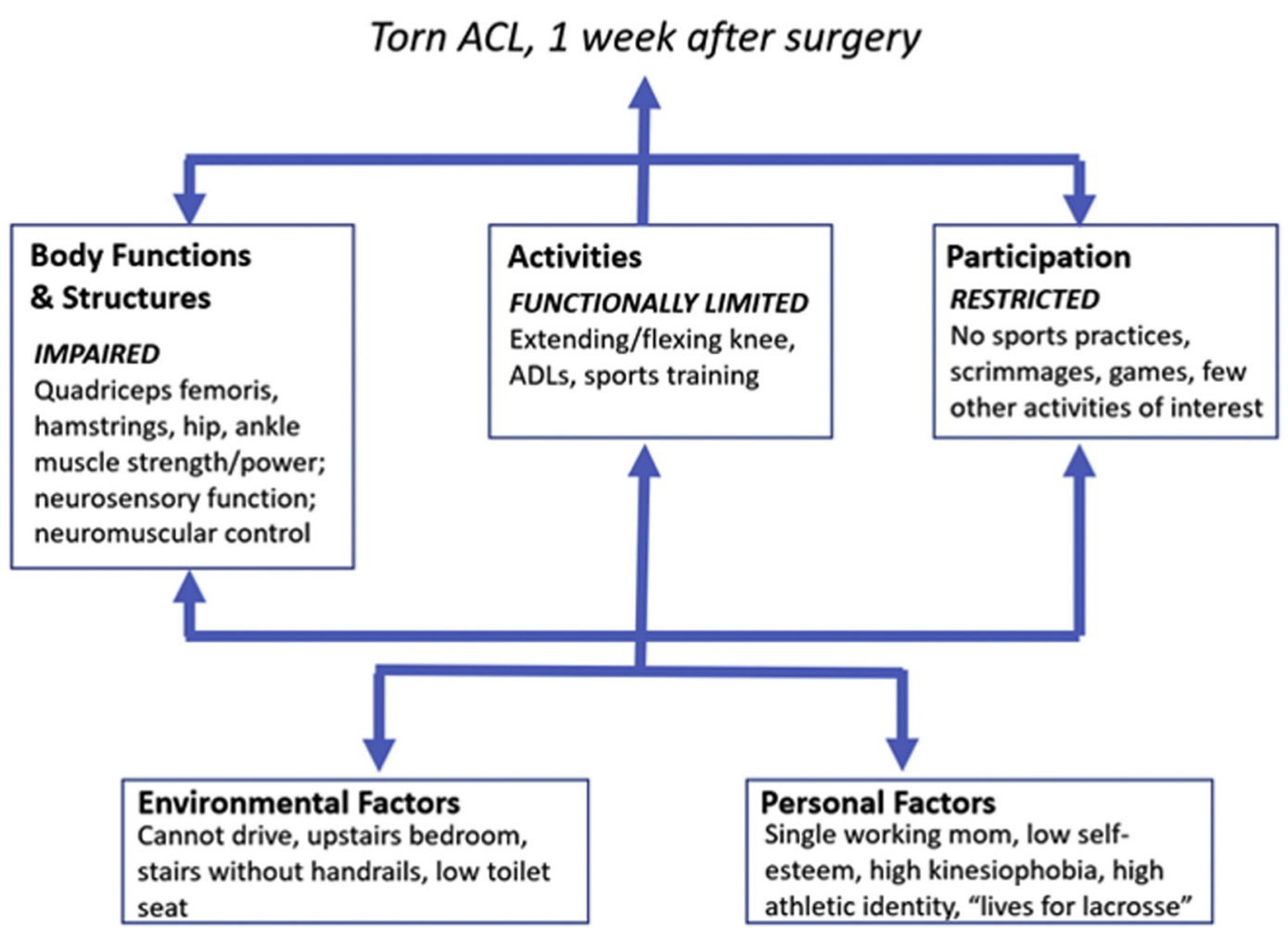

Fig 1. Comprehensive ICF example. ${ }^{54}$ ACL, anterior cruciate ligament; ADLs, activities of daily living; yo, years old.

temperature, altitude, or building design), social (institutions, laws, etc.), and personal (i.e., attitudes, beliefs, and values) environmental conditions. ${ }^{54}$

\section{Return-to-Play Decisions for Adolescent Athletes}

Determining the best time to return a psychologically fragile adolescent with a strong athletic identity back to unrestricted sports participation following knee injury, surgery, and rehabilitation is a difficult decision. The obsessive sports passion displayed by many adolescents, coupled with high athletic identities, in combination with having minimal, if any, recent actual sports training experiences during rehabilitation leads many to be released back to unrestricted sports participation too soon, with poor evidence supporting their release, and with high knee reinjury likelihood (Fig 2). A behavioral health counselor or sports psychologist referral may be useful as part of the comprehensive evaluation strategy encouraged by the ICF. ${ }^{36,54}$ Obsessive sports passion and minimal recent sports training experiences may also decrease the measurement validity of self-reported perceived function survey use among this patient group. ${ }^{47,55}$ Physical therapists and athletic trainers should combine several essential sport and positionspecific movement tasks to objectively confirm adolescent athlete physiological and psychological readiness from the perspective of the surgical knee, primary metabolic energy system-conditioning levels, and also, the athlete's ability to persevere and display resilience when confronted with unplanned, chaotic, and unpleasant psychological, as well as physiological stresses. These tasks should include multiple trials with some performed under fatigue conditions to better simulate actual sports practice or game situations. Improved policies and procedures are needed to establish more exact safe return-to-sports participation readiness guidelines following standard physical therapy. Poor decisions, based on incomplete, unidimensional information at this vital juncture in the adolescent athlete's life may set the stage for knee revision surgery or contralateral knee injury, increasing the chances that they will require additional surgeries, develop knee osteoarthritis, and accumulate related comorbidities, leading to greater adulthood disability.

\section{Conclusion}

When a particular developmental component is overused during adolescence, other components are probably underused or underdeveloped. This simple fact may lead to widely varying physiological and/or psychological imbalances. Restoration of homeostasis not just from a 
The Perfect Storm that may contribute to an adolescent athlete who has undergone ACL reconstruction and rehabilitation sustaining another knee injury: High athletic identity, high expectations, obsessive sports passion, past accomplishments, irrational reasoning with parental "outsourcing", inflated past accomplishment memories, and little or no recent sports training experiences.
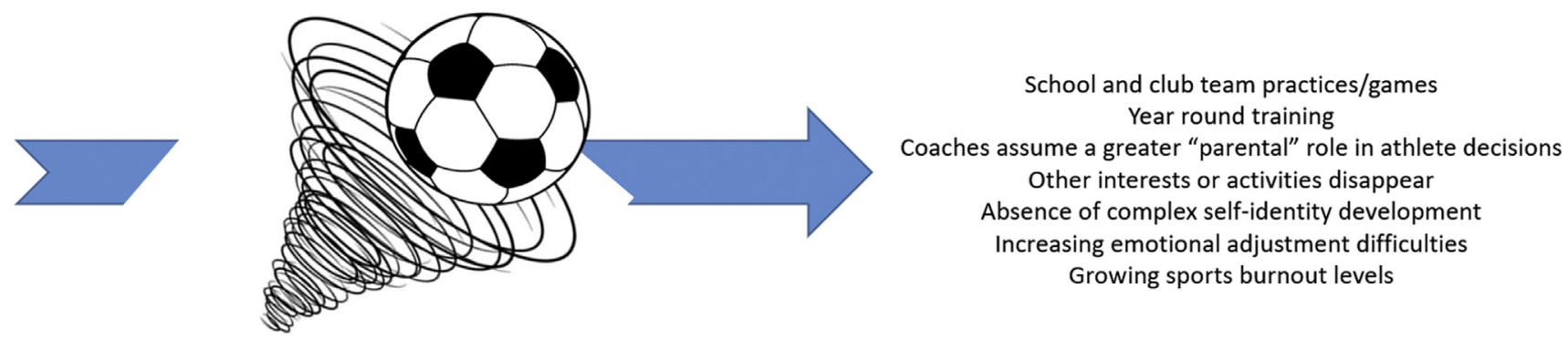

\begin{tabular}{|l|l|l|}
\hline Early Adolescence 11-14 yo & Middle Adolescence 15-17 yo & Late Adolescence 18-21 yo, and beyond... \\
\hline
\end{tabular}

Fig 2. The path to knee reinjury among adolescent athletes who possess a high sports identity may represent a "perfect storm". yo, years old.

physiological or musculoskeletal perspective, but inclusion of healthy psychological characteristics, might be most important for adolescent athlete injury prevention. In addition to the physical impairments, functional limitations, and disabilities that may occur post-ACL reconstruction and rehabilitation, clinicians should be aware of how self-identity, concept, and esteem changes among adolescents may help with self-protection. Recognizing the influence of musculoskeletal injury and surgery on the interaction between physical and psychological health is essential. Self-identity should originate from a variety of sources and roles; it should not be solely dependent on athletics.

\section{Acknowledgment}

The authors thank Dr. Lanny Johnson for his thoughtful insights and encouragement during manuscript development.

\section{References}

1. Nyland J, Brand E. Psychological factors in the ACL reconstruction population: Are they predictive of patient outcomes? In: Sanchis-Alfonso V, Monllau J, eds. The ACL-deficient knee: A problem-solving approach. London: Springer, 2013;189-199.

2. Jennison MH, Coleman AB, Feiertag RB, et al. Age limits of pediatrics. Pediatrics 1972;49:463.

3. Allen B, Waterman H. Stages of adolescence. American Academy of Pediatrics [cited Jul 29, 2021]. Available from, https://www.healthychildren.org/English/agesstages/teen/Pages/Stages-of-Adolescence.aspx.
4. Brenner JB, AAP Council on Sports Medicine and Fitness. Sport specialization and intensive training in young athletes. Pediatrics 2016;138:e20162148.

5. Johnson SB, Blum RW, Giedd JN. Adolescent maturity and the brain: The promise and pitfalls of neuroscience research in adolescent health policy. $J$ Adolesc Health 2009;45:216-221.

6. Sowell ER, Thompson PM, Holmes CJ, Jernigan TL, Toga AW. In vivo evidence for post-adolescent brain maturation in frontal and striatal regions. Nature Neurosci 1999;2:859-861.

7. Taylor J. Values in youth sports: Part I. Psychology Today [cited Jul 29, 2021]. Available from, https://www. psychologytoday.com/us/blog/the-power-prime/201711/ values-in-youth-sports-part-i.

8. Manfred T. Here are the odds that your kid becomes a professional athlete (Hint: They're small). Business Insider [cited Jul 29, 2021]. Available from, https://www. businessinsider.com/odds-college-athletes-becomeprofessionals-2012-2.

9. O'Shaughnessy L. 8 things you should know about sports scholarships. CBS News MoneyWatch [cited Jul 29, 2021 ]. Available from, https://www.cbsnews.com/news/8things-you-should-know-about-sports-scholarships/.

10. TBS staff. Athletic scholarships. June 15, 2021. The Best Schools [cited Jul 29, 2021]. Available from, https:// thebestschools.org/resources/college-finances/athleticscholarships/\#ncaa.

11. de Cervantes M, Grossman E. Don Quixote (translator). New York: Harper Collins, 2005.

12. Nyland J. Coming to terms with early sports specialization and athletic injuries. J Orthop Sports Phys Ther 2014;44: 389-390.

13. McKay CD, Cumming SP, Blake T. Youth sport: Friend or foe? Best Pract Res Clin Rheumatol 2019;33:141-157. 
14. Mostafavifar AM, Best TM, Myer GD. Early sport specialization: does it lead to long-term problems? $\mathrm{Br} J$ Sports Med 2013;47:1060-1061.

15. Brewer BW. Self-identity and specific vulnerability to depressed mood. J Pers 1993;61:343-364.

16. Gustafsson H, Kentta G, Hassmen P, Lundqvist C. Prevalence of burnout in competitive adolescent athletes. Sport Psychol 2007;21:21-37.

17. Rotella RJ, Heyman SR. Stress, injury, and the psychological rehabilitation of athletes. In: Williams JM, ed. Applied sport psychology: Personal growth to peak performance. 2nd ed. Palo Alto, CA: Mayfield, 1993;338-355.

18. Edison BR, Christino MA, Rizzone KH. Athletic identity in youth athletes: A systematic review of the literature. Int $J$ Environ Res Public Health 2021;18:7331.

19. Brewer BW, Cornelius AE, Stephan Y, Van Raalte J. Selfprotective changes in athletic identity following anterior cruciate ligament reconstruction. Psychol Sport Exerc 2010;11:1-5.

20. Lally P. Identity and athletic retirement: A prospective study. Psychol Sport Exerc 2007;8:85-99.

21. Brewer BW, Cornelius AE. Norms and factorial invariance of the athletic identity measurement scale (AIMS). Acad Athletic J 2001;15:103-113.

22. Brewer BW, Selby CL, Linder DE, Petitpas AJ. Distancing oneself from a poor season: Divestment of athletic identity. J Pers Interpers Loss 1999;4:149-162.

23. Brewer BW, Van Raalte JL, Linder DE. Athletic identity: Hercules' muscles or Achilles' heel? Int J Sport Psychol 1993;24:237-254.

24. Christino MA, Fantry AJ, Vopat BG. Psychological aspects of recovery following anterior cruciate ligament reconstruction. J Am Acad Orthop Surg 2015;23:501-509.

25. Markus H. Self-schemas and processing information about the self. J Pers Soc Psychol 1977;35:63-78.

26. Stryker S, Serpe RT. Identity salience and psychological centrality: Equivalent, overlapping, or complementary concepts? Soc Psychol Q 1994;57:16-35.

27. Martin EM, Horn TS. The role of athletic identity and passion in predicting burnout in adolescent female athletes. Sport Psychol 2013;27:338-348.

28. Lonsdale C, Hodge K. Temporal ordering of motivational quality and athlete burnout in elite sport. Med Sci Sports Exerc 2011;43:913-921.

29. Blinde EM, Stratta TM. The "sport career death" of college athletes: Involuntary and unanticipated sport exits. J Sport Behav 1992;15:3-20.

30. Kerr G, Dacyshyn A. The retirement experiences of elite, female gymnasts. J Appl Psychol 2000;12:115-133.

31. Sparkes AC. Athletic identity: An Achilles' heel to the survival of self. Qual Health Res 1998;8:644-664.

32. Grove JR, Lavallee D, Gordon S. Coping with retirement from sport: The influence of athletic identity. J Appl Sport Psychol 1997;9:191-203.

33. Shachar B, Brewer BW, Cornelius AE, Petitpas AJ. Career decision-making, athletic identity, and adjustment difficulties among retired athletes: A comparison between coaches and noncoaches. Kinesiol Slov 2004;10:71-85.
34. Petitpas AJ, Danish S, McKelvain R, Murphy S. A career assistance program for elite athletes. J Couns Dev 1990;70: 383-386.

35. Miller PS, Kerr GA. Conceptualizing excellence: Past, present, and future. J Appl Sport Psychol 2002;14: $140-153$.

36. Collinson JA, Hockey J. 'Working out' identity: Distance runners and the management of disrupted identity. Leis Stud 26:381-398.

37. Von Rosen P, Kottorp A, Friden C, Frohm A, Heijne A. Young, talented and injured: Injury perceptions, experiences, and consequences in adolescent elite athletes. Eur $J$ Sport Sci 2018;18:731-740.

38. Adler PA, Adler P. The gloried self: The aggrandizement and the constriction of self. Soc Psychol Q 1989;52:299-310.

39. Gustafsson H, Kenttä G, Hassmén P. Athlete burnout: An integrated model and future research directions. Int Rev Sport Exer Psychol 201 1;4:3-24.

40. Kuettel A, Boyle E, Schmid J. Factors contributing to the quality of the transition out of elite sports in Swiss, Danish, and Polish athletes. Psychol Sport Exer 2017;29:27-39.

41. Ronkainen NJ, Kavoura A, Ryba TV. A meta-study of athletic identity research in sport psychology: Current status and future directions. Int Rev Sport Exerc Psychol 2016;9:45-64.

42. Willard VC, Lavallee D. Retirement experiences of elite ballet dancers: Impact of self-identity and social support. Sport Exerc Perform Psychol 2016;5:266-279.

43. Lines G. Villains, fools or heroes? Sports stars as role models for young people. Leis Stud 2001;20:285-303.

44. Mitchell TO, Nesti M, Richardson D, Midgley AW, Eubank M, Littlewood M. Exploring athletic identity in elite-level English youth football: A cross-sectional approach. J Sports Sci 2014;32:1-6.

45. Weiss MR. Psychological aspects of sport-injury rehabilitation: A developmental perspective. J Athl Train 2003;38: 172-175.

46. Petrie TA. The moderating effects of social support and playing status on the life stress-injury relationship. J Appl Sport Psychol 1993;5:1-16.

47. Lewis M. The undoing project. New York: W.W. Norton \& Company, 2017.

48. Daly JM, Brewer BW, Van Raalte JL, Petitpas AJ, Sklar JH. Cognitive appraisal, emotional adjustment, and adherence to rehabilitation following knee surgery. J Sport Rehabil 1995;4:23-30.

49. Dye S. The knee as a biologic transmission with an envelope of function. Clin Orthop Relat Res 1996;325: $10-18$.

50. Nyland J, Abbott JD. Functional fitness, life stress, and transitions across the life span. In: Miller TW, ed. Handbook of stressful transitions across the lifespan. New York: Springer, 2010;605-623.

51. Nyland J, Fisher B, Brand E, Krupp R, Caborn DNM. Osseous deficits after anterior cruciate ligament injury and reconstruction: A systematic literature review with suggestions to improve osseous homeostasis. Arthroscopy 2010;26:1248-1257. 
52. Nyland J, Huffstutler A, Faridi J, Sachdeva S, Nyland M, Caborn D. Cruciate ligament healing and injury prevention in the age of regenerative medicine and technostress: Homeostasis revisited. Knee Surg Sports Traumatol Arthrosc 2020;28:777-789.

53. Wiese-Bjornstal DM, Smith AM, Shaffer SM, Morrey MA. An integrated model of response to sport injury: Psychological and sociological dynamics. J Appl Sport Psychol 1998;10:46-69.
54. Towards a common language for functioning, disability and health: ICF. World Health Organization (WHO) [cited Jul 29, 2021]. Available from, https://www.who.int/ classifications/icf/icfbeginnersguide.pdf.

55. Nyland J, Greene J, Carter S, Brey J, Krupp R, Caborn D. Return to sports bridge program improves outcomes, decreases ipsilateral knee re-injury and contralateral knee injury rates post-ACL reconstruction. Knee Surg Sports Traumatol Arthrosc 2020;28:3676-3685. 